\title{
Mucoceles of the oral cavity: A large case series (1994-2008) and a literature review
}

\author{
Dario Re Cecconi, Antonio Achilli, Marco Tarozzi, Giovanni Lodi, Federica Demarosi, Andrea Sardella, Antonio \\ Carrassi
}

DDS, MD, PHD. Università Degli Studi di Milano, Department of Medicine, Surgery and Dentistry, Unit of Oral Medicine, Oral Pathology and Gerodontology

Correspondence:

Unità di Medicina Orale

Patologia Orale ed Odontoiatria Geriatrica

Università degli Studi di Milano

Via Beldiletto 1, Milano 20142 Italy

d.rececconi@tin.it

\author{
Re Cecconi D, Achilli A, Tarozzi M, Lodi G, Demarosi F, Sardella A, Ca- \\ rrassi A. Mucoceles of the oral cavity: A large case series (1994-2008) \\ and a literature review. Med Oral Patol Oral Cir Bucal. 2010 Jul 1;15 \\ (4):e551-6. \\ http://www.medicinaoral.com/medoralfree01/v15i4/medoralv15i4p551.pdf
}

Received: $16 / 07 / 2009$ Accepted: 28/11/2009

\begin{abstract}
Objectives: Evaluating data of patients affected by oral mucoceles, examined at the Unit of Oral Medicine and Pathology of the University of Milan between January 1994 and December 2008.

Study Design: Concise review on oral mucoceles and analysis of the clinical files of patients who underwent excisional biopsy (patient age, medical history, diagnosis, date and site of the biopsy, histopathological diagnosis and recurrences if any).

Results: During the period June 1994-December 2008, 158 mucoceles were observed (93 males and 65 females), with the most frequent site being the lower lip $(53 \%)(\mathrm{p}=0.001$ by Fisher's test). The mean age of the patients was 31.9 years, with a peak of occurrence in the first four decades of life (75\%).

Conclusions: Mucoceles are lesions commonly seen in an oral medicine service, mainly affecting young people and lower lips.
\end{abstract}

Key words: Mucocele, ranula, treatment.

\section{Introduction}

Mucoceles, one of the most common nonmalignant masses of the oral cavity, are probably the most common disease of the accessory (minor) salivary glands (1). Mucoceles affect both genders $(1,2)$ in all age groups, with the peak age of incidence between 10 and 29 years (1); this, however, may be inaccurate because the asymptomatic nature of mucoceles does not always lead patients into seeking medical treatment (3).

This study presents a concise review of oral mucoceles and reports the clinical experience of the Unit of Oral Medicine and Pathology of the University of Milan at treating mucoceles from 1994 to 2008. 


\section{Materials and Methods}

For this study, we considered the clinical records of 3.427 patients who underwent an oral biopsy for diagnostic purposes at the Unit of Oral Medicine and Pathology of the University of Milan between January 1994 and December 2008. In the clinical records the following data have been considered:

- clinical diagnosis,

- medical history,

- date of biopsy,

- patient age,

- biopsy site,

- histopathological diagnosis

- recurrences (if any).

For some patients, we were unable to find the necessary information. In the case of recurrences, the clinical reports were analyzed to determine if the lesion occurred at the same site and to consider whether it was a recurrence or another mucocele that affected the same patient.

Data on age and onset site of patients with mucoceles were compared with the total number of biopsies performed at the same unit during the study period. In addition, our results were compared with data reported in the international literature.

\section{Results}

Of the 3.427 biopsies, 158 were mucoceles: 93 affected males (59\%) and 65 females (41\%). Regarding the location of the mucoceles, 84 (53\%) affected the lower lip, 8 $(5 \%)$ the oral floor, $6(4 \%)$ the cheeck, $3(2 \%)$ the upper lip, $1(1 \%)$ the palate, and $1(1 \%)$ the ventral surface of the tongue. Of the biopsies, 155 were from the lower lip, 22 the upper lip, 49 the ventral surface of the tongue, 631 the cheeck, 148 the palate, and 71 the oral floor. Mucoceles seemed to develop in the lower lip significantly more often ( $\mathrm{p}=0.0001$ by Fisher's test) compared to other locations (Fig. 1).

Patients with mucoceles were between 6 and 85 years old, with an average of 31.9 years. Examining the distribution of lesions according to age, mucoceles were most common in patients in the first four decades of life (75\%).

Examining the monthly distribution within the year, no seasonal difference was observed.

Six recurrences were reported in six patients. The time between the two surgical excisions ranged from 20 days to 6 years. In one case, the lesion affected the oral floor and was considered a ranula.

Patients who underwent biopsies during the study period were between 3 and 100 years old, averaged of 54.7 years. Compared to the average age of the patients with mucoceles (31.9 years), the difference was significant $(\mathrm{p}=0.0001$ by t-test). Considering biopsies and age (Fig. 2), patients that underwent a biopsy in the unit were between 41 and 70 years old.

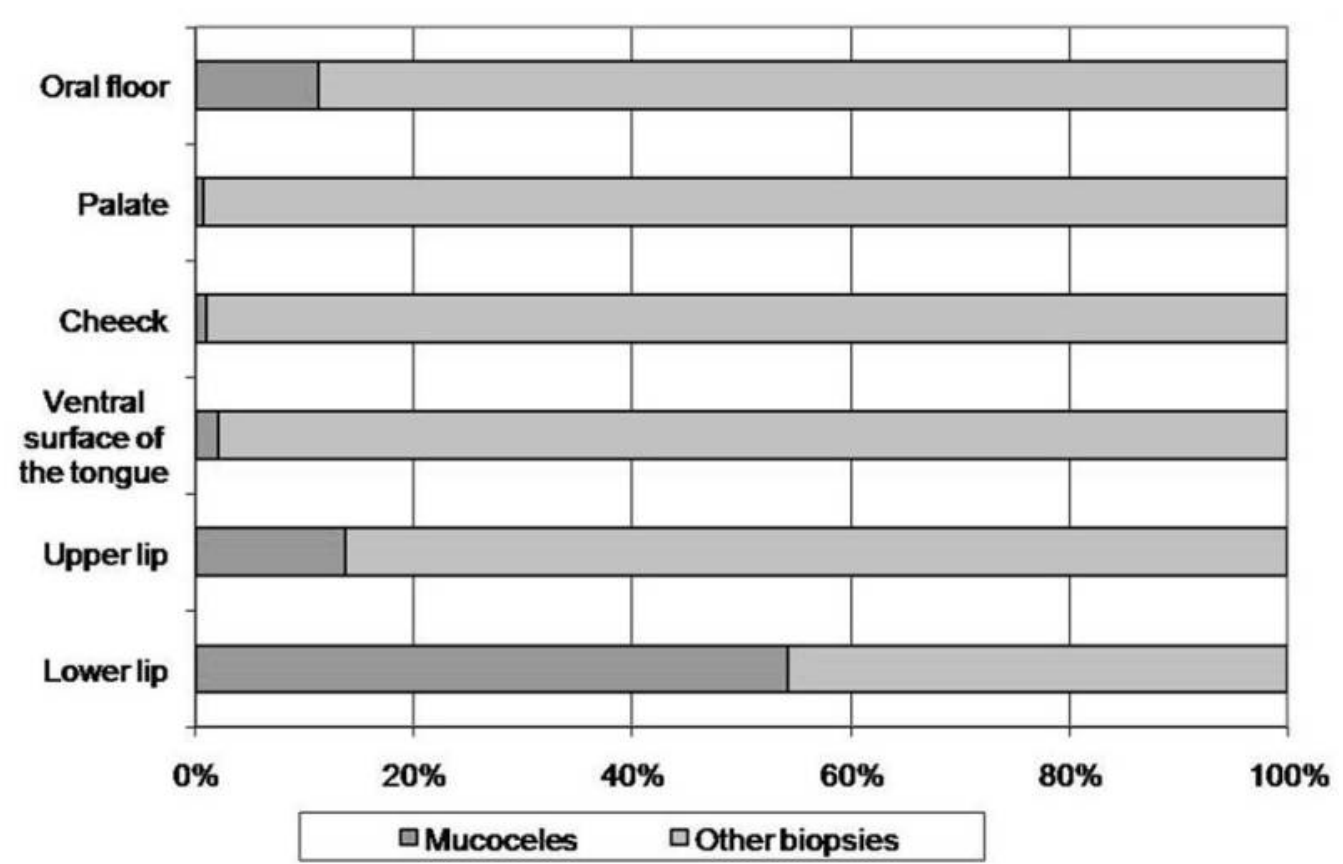

Fig. 1. Graphic on the distribution of mucoceles and other biopsies by locations of surgical excision. 


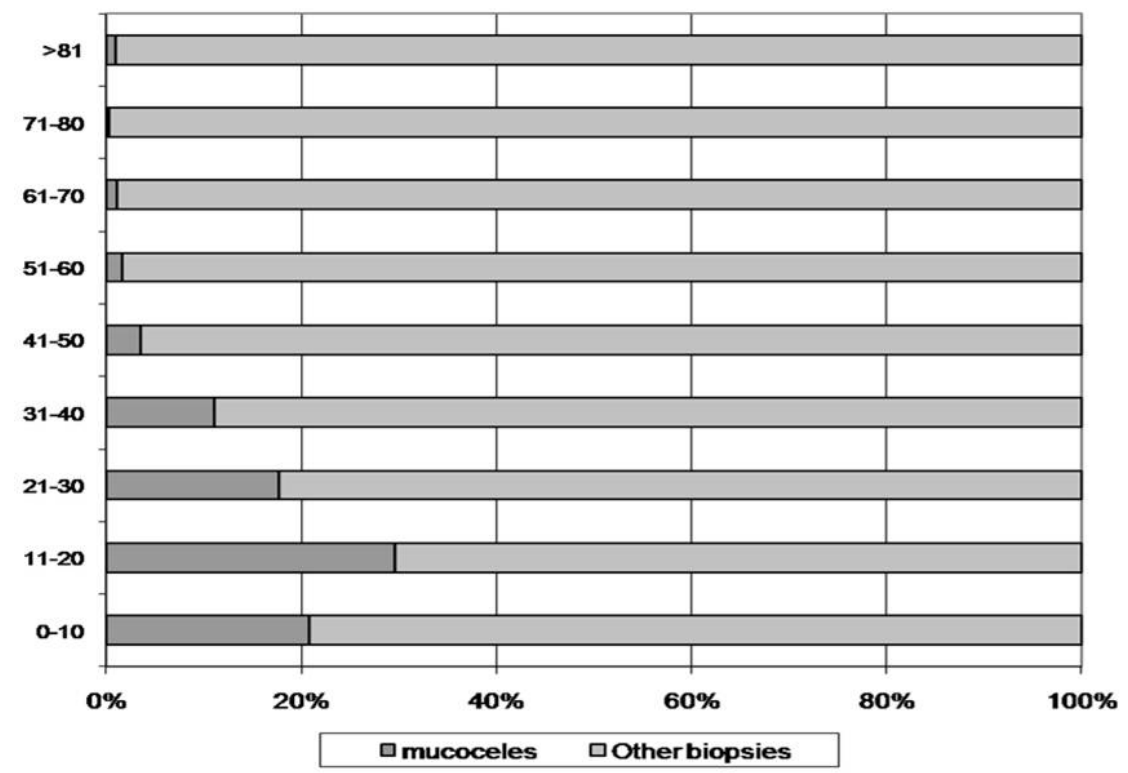

Fig. 2. Graphic on distribution of mucoceles and other biopsies by age.

\section{Definition and Etiopathogenesis}

Mucoceles are cavities filled in with mucus and lined by epithelium or covered by granulation tissue $(1,2)$.

Ranulae are considered a variant of mucoceles that arises in the oral floor. The name derives from the typical swelling that resembles the air sacs of the frog $(1,4)$.

\section{Extravasation cysts}

Mucoceles can be classified as extravasation or retention cysts $(1,5)$. Mucoceles are mostly caused by the extravasation of mucus followed by trauma to the duct of a salivary gland. Trauma to the excretory duct of a minor salivary gland can rupture the duct, causing the extravasation and accumulation of saliva in the surrounding connective tissue and an inflammatory reaction. An extravasation cyst is a delimited area surrounded by granulation tissue containing pools of extravasated mucus (i.e., pseudocyst). Numerous animal studies have shown a relationship between trauma and salivary mucocele formation (6). This relationship has also been demonstrated in humans (7).

Teenagers and children are most commonly affected by mucoceles.

The lower lip is the most frequent site for mucoceles, where $60-80 \%$ occur (6). Other typical sites are: cheek, ventral surface of the tongue (2), oral floor, and retromolar pad area.

\section{Retention cysts}

Retention cysts result from ductal obstruction due to sialolithiasis, periductal scars or invasive tumors. The narrowing of the ductal opening does not allow an adequate salivary flow, with subsequent ductal distention presented as a mucosal swelling (1). A ductal obstruction might also cause enlargement of a salivary gland (8).
Retention cysts, less common than extravasation cysts, usually affect older patients (6) and are rarely found on the lower lip. The most frequent sites are: upper lip, palate, cheek, oral floor and maxillary sinus (6).

Ductal narrowing can occur in patients who indulge in frequent mouth washing with hydrogen peroxide, deodorant mouthwashes, or antiplaque solutions, which can be highly irritating (1). Tartar-control toothpastes are also a possible cause of irritation (1).

Retention cysts appear similar to extravasation cysts $(1,2)$. They are lined by duct epithelium, which can be pseudo-layered with columnar or cuboidal cells (1). The cyst cavity contains mucus cells or fragments of sialolithiasis, and the connective tissue of the cyst is slightly inflamed.

\section{Clinical Aspects}

Mucoceles present as soft, smooth, painless swellings, ranging from deep blue to the normal color of the oral mucosa (pink) (Fig. 3). The deep blue color results from tissue cyanosis and vascular congestion associated with the stretched overlying tissue and the translucent character of the accumulated fluid beneath. A decrease in size may follow rupture of the lesion and subsequent mucin accumulation or reabsorption of saliva deposits. An increase in saliva production can cause the lesion to reform (2).

Mucoceles rarely cause significant problems. Discomfort, interference with speech, mastication, swallowing and external swelling may occur depending on the size and location of mucoceles (1). 


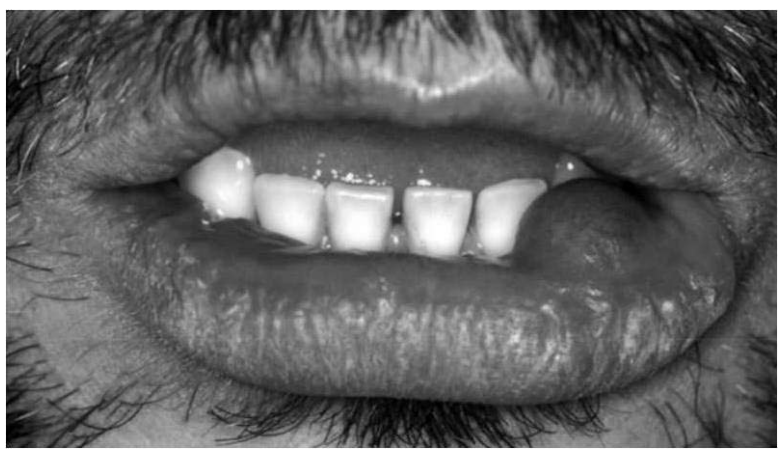

Fig. 3. Typical translucent mucocele on the lower lip mucosa.

\section{Diagnosis}

The case history and an objective examination of the lesion are crucial for diagnosing mucoceles correctly.

In particular cases, the diagnosis may require traditional radiography, ultrasonography, or advanced diagnostic methods (computed tomography (CT) and magnetic resonance imaging (MRI) to better visualize form, diameter, position of the lesion relative to adjacent organs (9).

Ultrasonography shows mucoceles as cystic masses that sometimes contain fibrillar processes produced by fibroblasts seen in minimal numbers within the mucinous area (septa)

Fine-needle aspiration is a useful diagnostic technique for evaluating patients with salivary gland nodules and enlargement (10). Differentiating between mucoceles and vascular lesions preoperatively is very important because large angiomas mistaken for mucoceles can result in major bleeding if removed (10).

\section{Treatment}

The surgical approach to mucoceles and ranulae is the most common treatment and depends on various factors: the size of the lesion is the most important (11). There are three possible surgical approaches to manage mucoceles of the lips, cheeks, and palate (1):

1) Completely excision

2) Marsupialization

3) Dissecting

Lesion can be excised completely or treated with an unroofing procedure (marsupialization) because excision or dissection is problematic and risks vital structures such as the labial branch of the mental nerve. This technique should also be used when treating mucoceles that affect the palate, as the surgical access can be problematic. Dissecting the mucoceles along with the mucous glands serving them (1). The literature contains many articles that compare the different techniques, but no specific or ideal treatment for sublingual ranulae is recommended. The most predictable method of eradicating a ranula is to remove the associated sublingual gland because this rarely results in recurrences (approximately 1\%) (12), even if it is very invasive (11).
As ranulae can resolve spontaneously, especially in pediatric patients, Pandit and Park (4) suggest observing the lesion for 5 months before proceeding with surgical treatment because this is an adequate time for spontaneous resolution of the lesion (4). Simple incision with subsequent drainage of the cavity is unsuccessful in $100 \%$ of the cases. Takimoto et al. suggested injecting fibrin glue into the cystic space of the ranula after it had been evacuated by aspiration; because this prevents collapse of the wall of the cyst during surgery and simplifies the surgical procedure by clearly outlining the area and sharply delineating its thin wall (13). To reduce the risk of recurrences with marsupialization, this technique is used frequently. Moreover, it is now preferred to proceed with marsupialization associated with the use of iodoform gauze packing, a method (14), that prevents the early closure of the cavity; if left in place for 7 to 10 days, the gauze allows the cyst to exfoliate naturally (14). A retrospective study (15), reported problems and recurrences in patients with ranulae. The results have been highlighted in (Table 1).

Cryosurgery is another effective method. The procedure uses a gas expansion cryoprobe with a 10-mm-diameter round tip. Bodner and Tal (1991) performed three applications at the same site in a single session without the need of local anesthesia. The selected cryodose for each application was a $30-\mathrm{s}$ freeze at $-81^{\circ} \mathrm{C}$ followed by an approximately 1-min thaw. Problems that can arise include potential damage to the lingual nerve and submandibular duct $(4,16)$.

Carbon dioxide (CO2) lasers have been successfully used to treat various soft tissue pathologies in oral and maxillofacial surgery. The reported advantages include a bloodless operating field, precise incision, easy surgery, decreased postoperative swelling, and minimized scar tissue. No particular complications in the postoperative period and no hemorrhagic episodes seem to occur. Other benefits are reduced edema and postoperative pain. From an aesthetic and functional perspective, the results with $\mathrm{CO} 2$ lasers are satisfactory $(5,17)$.

The sclerosing agent OK-432 (Picibanil; Chugai Pharmaceutical, Tokyo, Japan) is a lyophilized mixture of a low virulence strain of Streptococcus pyogenes incubated with benzylpenicillin (18). A single intralesional injection, preceded by aspiration of the cyst fluid, causes the pseudocyst or cyst wall to collapse and triggers a severe inflammatory reaction of the wall that results in marked fibrosis, which seals the leak in the perforated gland capsule and prevents further mucus extravasation. The result is acinar atrophy and consequent healing $(11,19)$. Only a few articles in the international scientific literature describe this method (20) (Table 2). The side effects of OK-432 include shock $(0.05 \%)$, persistent fever $(21.9 \%)$, and local inflammatory symptoms (19). 
Table 1. Complication rates associated with procedures for treatment of ranula.

\begin{tabular}{|l|c|c|c|c|c|}
\hline & \multicolumn{5}{|l|}{ SURGICAL PROCEDURES } \\
\hline \multicolumn{1}{|c|}{ COMPLICATIONS } & M & ER & ESLG & ESLGR & TOTAL \\
\hline Damage of Wharton duct & $0(0 \%)$ & $0(0 \%)$ & $5(1,40 \%)$ & $6(2,82 \%)$ & $\mathbf{1 1}(\mathbf{1 , 8 2} \%)$ \\
\hline Bleeding or hematoma & $0(0 \%)$ & $0(0 \%)$ & $1(0,28 \%)$ & $4(1,88 \%)$ & $\mathbf{5 ( 0 , 8 3 \% )}$ \\
\hline Dehiscence of wound & $0(0 \%)$ & $0(0 \%)$ & $3(0,84 \%)$ & $3(1,41 \%)$ & $\mathbf{6 ( 0 , 9 9 \% )}$ \\
\hline Postoperative infection & $0(0 \%)$ & $0(0 \%)$ & $1(0,28 \%)$ & $4(1,88 \%)$ & $\mathbf{5 ( 0 , 8 3 \% )}$ \\
\hline Numbness of tongue & $0(0 \%)$ & $1(3,85 \%)$ & $6(2,10 \%)$ & $15(11,63 \%)$ & $\mathbf{2 2}(\mathbf{4 , 8 9 \% )}$ \\
\hline Recurrence & $6(66,67)$ & $15(57,69 \%)$ & $3(1,05 \%)$ & $2(1,55 \%)$ & $\mathbf{2 6}(\mathbf{5 , 7 8 \% )}$ \\
\hline
\end{tabular}

M, marsupialization; ER, excision of ranula; ESLG, excision of sublingual gland; ESLGR excision of sublingual gland and ranula.

Table 2. Article regards OK-432 therapy for mucoceles.

\begin{tabular}{|l|c|c|c|c|}
\hline \multicolumn{2}{|c|}{ Reference } & No of patients & $\begin{array}{c}N^{\circ} \text { of total } \\
\text { regression }\end{array}$ & $\begin{array}{c}N^{\circ} \text { of partial } \\
\text { regression }\end{array}$ \\
\hline Lee HM & 2006 & 13 & $9(69,3 \%)$ & $3(23 \%)$ \\
\hline Roh JL & 2006 & 26 & $20(77 \%)$ & - \\
\hline Fukase S & 2003 & 32 & $31(97 \%)$ & - \\
\hline Muraoka MD & 2002 & 3 & $3(100 \%$ & - \\
\hline Watanable & 2002 & 1 & $1(100 \%)$ & - \\
\hline
\end{tabular}

\section{Conclusion}

In our series, no gender difference were observed in the incidence of mucoceles, as reported by Baurmash (1) and others. Regarding the age of onset, patients less than 40 years old were most affected, which is similar to the reported peak incidence between 10 and 39 years (1). No previous study has reported a seasonal occurrence as with our findings.

Nevertheless, our study has limitations, as do all retrospective studies. For example, determining the locations of mucoceles in 55 patients proved impossible because clinical data were missing or the location was not given in the histopathological reports. In younger patients correlating the eventual trauma with orthodontic treatment was not possible because of missing data. In addition, the dimensions of mucoceles were frequently not reported.

In the records that were analyzed, the differences between retention and extravasation cysts were not specified. Therefore, estimating the incidence of retention and extravasation cysts in our patients was not achievable.

In the literature, different treatments are reported according to the size of the lesion. In our series, we used surgical excision only because we treated primarily small to medium-sized lesions. Furthermore, we could find no reported data on the recurrence frequency of mucoceles. Therefore, we could not compare our observed rate of recurrence $(3.95 \%$ in 152 patients between 1994 and 2008) with other published figures.

\section{References}

1. Baurmash HD. Mucoceles and ranulas. J Oral Maxillofac Surg. 2003;61:369-78.

2. Guimarães MS, Hebling J, Filho VA, Santos LL, Vita TM, Costa CA. Extravasation mucocele involving the ventral surface of the tongue (glands of Blandin-Nuhn). Int J Paediatr Dent. 2006;16:435-9.

3. Poker ID, Hopper C. Salivary extravasation cyst of the tongue. Br J Oral Maxillofac Surg. 1990;28:176-7.

4. Pandit RT, Park AH. Management of pediatric ranula. Otolaryngol Head Neck Surg. 2002;127:115-8.

5. Yagüe-García J, España-Tost AJ, Berini-Aytés L, Gay-Escoda C. Treatment of oral mucocele-scalpel versus CO2 laser. Med Oral Patol Oral Cir Bucal. 2009;14:e469-74.

6. Harrison JD. Salivary mucoceles. Oral Surg Oral Med Oral Pathol. 1975;39:268-78

7. Catone GA, Merrill RG, Henny FA. Sublingual gland mucus-escape phenomenon treatment by excision of sublingual gland. J Oral Surg. 1969;27:774-86.

8. Mehta D, Willging JP. Pediatric salivary gland lesions. Semin Pediatr Surg. 2006;15:76-84.

9. Shah GV. MR imaging of salivary glands. Magn Reson Imaging Clin N Am. 2002;10:631-62.

10. Layfield LJ, Gopez EV. Cystic lesions of the salivary glands: cytologic features in fine-needle aspiration biopsies. Diagn Cytopathol. 2002;27:197-204.

11. Baurmash HD. A case against sublingual gland removal as primary treatment of ranulas. J Oral Maxillofac Surg. 2007;65:117-21.

12. McGurk M. Management of the ranula. J Oral Maxillofac Surg. 2007:65:115-6.

13. Takimoto T, Ishikawa S, Nishimura T, Tanaka S, Yoshizaki T, Komori T, et al. Fibrin glue in the surgical treatment of ranulas. Clin Otolaryngol Allied Sci. 1989;14:429-31.

14. Baurmash HD. Marsupialization for treatment of oral ranula: a second look at the procedure. J Oral Maxillofac Surg. 1992;50:1274-9.

15. Zhao YF, Jia J, Jia Y. Complications associated with surgical management of ranulas. J Oral Maxillofac Surg. 2005;63:51-4. 
16. Bodner L, Tal H. Salivary gland cysts of the oral cavity: clinical observation and surgical management. Compendium. 1991;12:150, $152,154-6$.

17. Niccoli-Filho W, Morosolli AR. Surgical treatment of ranula with carbon dioxide laser radiation. Lasers Med Sci. 2004;19:12-4.

18. Rho MH, Kim DW, Kwon JS, Lee SW, Sung YS, Song YK, et al. OK 432 sclerotherapy of plunging ranula in 21 patients: it can be a substitute for surgery. AJNR Am J Neuroradiol. 2006;27:1090-5.

19. Muraoka M, Taniguchi T, Harada T. A new conservative treatment for retention cyst of the lip: OK-432 injection. Br J Plast Surg. 2002;55:533.

20. Roh JL. Primary treatment of ranula with intracystic injection of OK-432. Laryngoscope. 2006;116:169-72. 